\title{
Фотоанодирование $n$-Si в присутствии перекиси водорода: зависимость от напряжения
}

\author{
(С) Г.В. Ли, Е.В. Астрова, А.И. Лихачев \\ Физико-технический институт им. А.Ф. Иоффре, \\ 194021 Санкт-Петербург, Россия \\ E-mail: GalyaFedulova@mail.ioffe.ru
}

(Получена 23 апреля 2018 г. Принята к печати 25 мая 2018 г.)

\begin{abstract}
Исследованы закономерности процесса электрохимического травления $n$-Si с низким уровнем легирования в условиях освещения обратной стороны образца при использовании раствора с малой концентрацией HF и высокой концентрацией перекиси водорода. Полученные данные сравниваются с данными для контрольного электролита, не содержащего $\mathrm{H}_{2} \mathrm{O}_{2}$. Исследованы морфология макропор, скорость их роста, пористость, эффективная валентность и количество растворенного кремния в зависимости от приложенного напряжения. Проведены исследования кинетики процесса при низком и высоком напряжении смещения. Обнаружено, что при одинаковой подсветке начальный фототок в перекисном электролите в $\sim 2$ раза меньше, чем в электролите, не содержащем $\mathrm{H}_{2} \mathrm{O}_{2}$, что позволяет утверждать о более низкой квантовой эффективности фототока. Однако с увеличением времени травления ток в перекисном электролите сильно возрастает и становится больше, чем в контрольном электролите. Установлено, что в присутствии $\mathrm{H}_{2} \mathrm{O}_{2}$ скорость роста макропор в глубину возрастает более чем в 2 раза, а пористость уменьшается. Вертикальные каналы макропор имеют диаметр, меньший, чем в случае макропор, образовавшихся в водном электролите, и их стенки плохо пассивированы, что обусловливает ветвление и появление вторичных мезопор, число которых возрастает с напряжением. Эффективная валентность растворения кремния (выход по току) в присутствии $\mathrm{H}_{2} \mathrm{O}_{2}$ уменьшается до значений, меньших чем 2. Полученные результаты интерпретируются в рамках моделей Геришера и Коласинского.
\end{abstract}

DOI: 10.21883/FTP.2019.01.46999.8897

\section{1. Введение}

Добавление окисляющего агента в раствор плавиковой кислоты существенно изменяет процесс электрохимического травления $n-\mathrm{Si}$. Так, электролиты на основе перекиси водорода позволяют ускорить растворение электронного кремния как в темноте $[1,2]$, так и в режиме подсветки обратной стороны образца $[3,4]$. При низких напряжениях и малой концентрации HF макропоры в $n-\mathrm{Si}(100)$ с низким уровнем легирования сохраняют вертикальные стенки, и тем самым делают их похожими на макропоры, сформированные в электролите на основе водного раствора плавиковой кислоты [3]. При высоком напряжении в режиме пробоя появляется интенсивное образование вторичных пор как при высокой [5], так и при низкой концентрации HF [6]. Характерной чертой фотоанодирования в перекисном электролите является снижение эффективной валентности вплоть до $n=1$. В предыдушей нашей работе [6] ставилась задача сформировать иерархическую пористую структуру, состоящую из основных каналов и вторичных мезопор меньшего диаметра. Для этого изучался пробойный режим анодирования и влияние на него интенсивности света при использовании электролита с низкой концентрацией $\mathrm{HF}$ и высокой концентрацией $\mathrm{H}_{2} \mathrm{O}_{2}$. Настоящее исследование посвящено изучению фотоанодирования в том же электролите в зависимости от напряжения на интерфейce Si-электролит и сравнению его с процессом, протекающим в водном растворе HF той же концентрации.

\section{2. Эксперимент}

Исходным материалом для экспериментов служил $n-\mathrm{Si}(100)$, предназначенный для изготовления солнечных элементов, с удельным сопротивлением 3 Ом · см с текстурированной поверхностью (см. работы [6,7]). Анодирование проводилось в электролите, состоящем из 4\% раствора $\mathrm{HF}$ в $30 \%$ перекиси водорода (перекисный электролит). Для сравнения использовался 4\% раствор HF в воде (водный электролит). В оба электролита добавлялось 5\% $\mathrm{C}_{2} \mathrm{H}_{5} \mathrm{OH}$. Электрохимическое травление проводилось при постоянном смещении в условиях освещения обратной стороны образца собственным светом. Высокое время жизни неосновных носителей заряда (дырок) составляло 1 мс, что соответствует диффузионной длине, которая во много раз превышает толщину пластины 180 мкм. Таким образом, рекомбинационные потери при диффузии фотодырок от тыльной стороны пластины к границе Si-электролит были малы. Использовался режим постоянного тока $I=16 \mathrm{MA}\left(j=5.7 \mathrm{MA} / \mathrm{cm}^{2}\right)$, постоянство которого во времени обеспечивалось за счет обратной связи, изменяющей интенсивность подсветки, и режим постоянной подсветки. Заметим, что интенсивность света и фототок, протекающий через интерфейс, прямо пропорционален напряжению $E$ на светодиодной подсвечивающей матрице. Это напряжение в режиме $I=$ const со временем изменялось от $E_{0}$ в начале процесса анодирования до $E_{f}$ в конце, а в режиме $E=$ const со временем изменялся ток от $I_{0}$ до $I_{f}$. Компьютеризированная установка SiPor 
Таблица 1. Условия анодирования и параметры пористой структуры в зависимости от напряжения. Травление в перекисном электролите в режиме постоянного тока в течение 40 мин

\begin{tabular}{c|c|c|c|c|c|c|c|c|c|c|c}
\hline Образец & $U, \mathrm{~B}$ & $p, \%$ & $l$, мкм & $r$, мкм/мин & $n$ & $E_{0}, \mathrm{~B}$ & $E_{f}, \mathrm{~B}$ & $E_{\mathrm{av}}, \mathrm{B}$ & $j, \mathrm{мA} / \mathrm{cм}^{2}$ & $\Delta m$, мг & $\Delta m / t$, мг/мин \\
\hline $22 \mathrm{M} 3$ & 0.5 & 17 & 56 & 1.4 & 1.80 & 4.8 & 2.8 & 4.3 & 5.7 & 6.2 & 0.16 \\
$22 \mathrm{M} 2$ & 1.0 & 13 & 75 & 1.875 & 1.75 & 4.4 & 2.6 & 3.5 & 5.7 & 6.4 & 0.16 \\
$22 \mathrm{M} 6$ & 2.0 & 15 & 63 & 1.575 & 1.77 & 4.0 & 2.4 & 3.1 & 5.7 & 6.3 & 0.16 \\
$19 \mathrm{M} 2$ & 3.0 & 17 & 60 & 1.5 & 1.69 & 4.6 & 2.7 & 3.6 & 5.7 & 6.6 & 0.17 \\
$24 \mathrm{M} 2$ & 5.0 & 15 & 70 & 1.75 & 1.64 & 4.4 & 2.3 & 3.2 & 5.7 & 6.8 & 0.17 \\
$22 \mathrm{M} 4$ & 7.0 & 14 & 74 & 1.85 & 1.69 & 3.9 & 2.1 & 2.8 & 5.7 & 6.3 & 0.16 \\
$24 \mathrm{M} 1$ & 9.0 & 15 & 70 & 1.75 & 1.64 & 4.2 & 2.1 & 3.0 & 5.7 & 6.8 & 0.17 \\
$22 \mathrm{M} 1$ & 12.0 & 16 & 69 & 1.725 & 1.55 & 3.1 & 2.1 & 2.3 & 5.7 & 7.2 & 0.18
\end{tabular}

Таблица 2. Условия анодирования и параметры пористой структуры в зависимости от напряжения. Травление в водном электролите в режиме постоянного тока в течение 70 мин

\begin{tabular}{c|c|c|c|c|c|c|c|c|c|c|c}
\hline Образец & $U, \mathrm{~B}$ & $p, \%$ & $l$, мкм & $r$, мкм/мин & $n$ & $E_{0}, \mathrm{~B}$ & $E_{f}, \mathrm{~B}$ & $E_{\mathrm{av}}, \mathrm{B}$ & $j, \mathrm{мA} / \mathrm{cм}^{2}$ & $\Delta m, \mathrm{мг}$ & $\Delta m / t, \mathrm{мг} / \mathrm{мин}$ \\
\hline 27In1 & 0.5 & 37 & 30 & 0.43 & 2.26 & 2.1 & 6.3 & 5.4 & 5.3 & 7.3 & 0.10 \\
27 In2 & 1.0 & 26 & 49 & 0.70 & 2.3 & 2.4 & 2.9 & 2.8 & 5.7 & 8.5 & 0.12 \\
$27 I n 3$ & 2.0 & 23 & 53 & 0.76 & 2.41 & 1.9 & 2.7 & 2.6 & 5.7 & 8.1 & 0.12 \\
$27 I n 5$ & 4.0 & 23 & 53 & 0.76 & 2.44 & 2.0 & 2.6 & 2.5 & 5.7 & 8.0 & 0.11 \\
$27 I n 4$ & 5.0 & 23 & 53 & 0.76 & 2.41 & 2.6 & 3.0 & 2.9 & 5.7 & 8.1 & 0.12 \\
3I11 & 9.0 & 23 & 57 & 0.81 & 2.22 & 2.3 & 2.0 & 2.1 & 5.7 & 8.8 & 0.13 \\
26 In1 & 12.0 & 24 & 54 & 0.77 & 2.25 & 3.6 & 2.1 & 2.9 & 5.7 & 8.7 & 0.12
\end{tabular}

фирмы ЕT\& TE (Германия) позволяла записывать во времени $(t)$ величину протекающего тока $(I)$, напряжения на границе кремний-электролит $(U)$ и напряжение $E$. Температура анодирования составляла $15^{\circ} \mathrm{C}$. Пористость $(p)$, эффективную валентность $n$ и скорость растворения кремния $(\Delta m / t)$, где $\Delta m-$ потеря массы образца, находили гравиметрическим методом (см. соответствующие формулы работы [6,7]). Скорость продвижения пористого фронта в глубь подложки находили из отношения глубины пор $(l)$ ко времени анодирования $(t)$ : $r=l / t$. С учетом более высокой скорости травления в перекисном электролите использовалось разное время анодирования для сравниваемых электролитов: в течение $t=40$ мин в перекисном электролите и 70 мин в водном электролите. В работе [6] было показано, что даже при высоком напряжении длительность процесса анодирования в водном электролите не влияет на параметры $p, n, r$ и $\Delta m / t$, а определяется плотностью тока травления. Для обоих электролитов резкое возрастание темнового тока, указывающее на пробой, начиналось при напряжении $U>8 \mathrm{~B}$. В табл. 1 и 2 приводятся результаты этой серии экспериментов.

\section{3. Морфология пор}

На рис. 1-4 приведено изображение поперечного сечения пористых структур (плоскость (110)), полученное с помощью сканирующего электронного микроскопа (СЭМ) для образцов, травившихся при разном напряжении.
Из рис. 1 и 2 видно, что при малых напряжениях смещения $U<1 \mathrm{~B}$ в обоих электролитах наблюдается образование редких пор большого диаметра, так называемых бутылкообразных пор, не имеющих боковых ветвей [8]. При более высоких напряжениях видно существенное изменение морфологии: образуются более частые макропоры с вертикальными стенками, в верхней части которых начинают появляться вторичные поры, распространяющиеся в горизонтальной плоскости и имеющие меньший диаметр, чем основные каналы; будем называть их так же, как в работе [6], пробойными мезопорами (рис. 3 и 4). При $U=4-5$ В для водного и $U=2-3$ В для перекисного электролитов появляются боковые макропоры, растущие под углом к оси основных каналов (наклонные ветви). Для перекисного электролита при увеличении напряжения их длина и угол наклона уменьшаются, и они складываются как крылья, но при этом не исчезают совсем. Для водного электролита ветвление гораздо менее выражено, а при $U>5$ В оно полностью исчезает. Для обоих электролитов диаметр основных каналов и среднее расстояние между ними уменьшается с напряжением.

На рис. 5 показан вид сверху образцов, травившихся при разном напряжении в водном и перекисном электролитах, с поверхности которых был удален слой толщиной $\sim 15$ мкм (методом шлифовки и полировки). Из рисунков видно, что диаметр основных каналов, сформировавшихся при анодировании в перекисном электролите, меньше, чем в водном. В перекисном электролите даже при низком напряжении образует- 


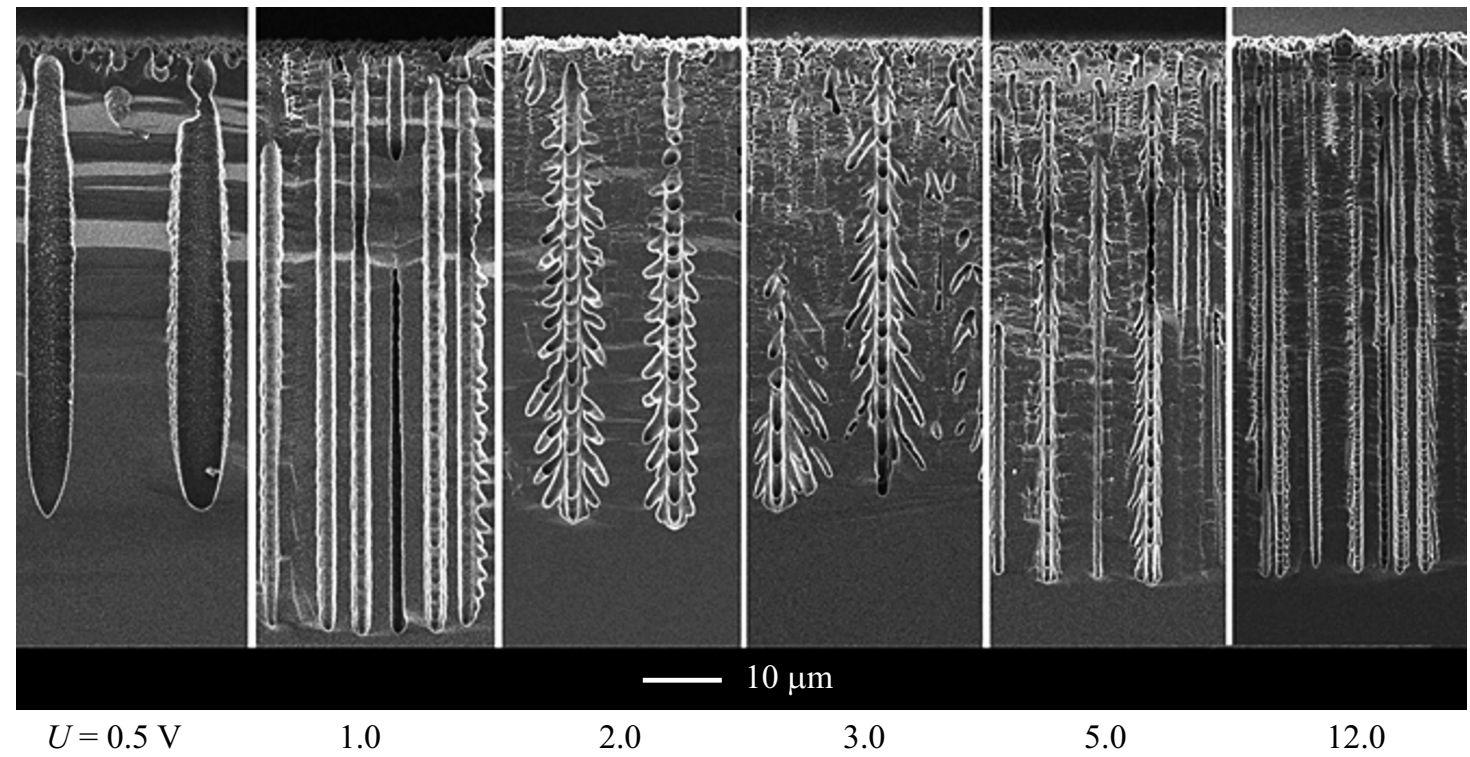

Рис. 1. Зависимость морфологии пор от напряжения при анодировании в перекисном электролите.

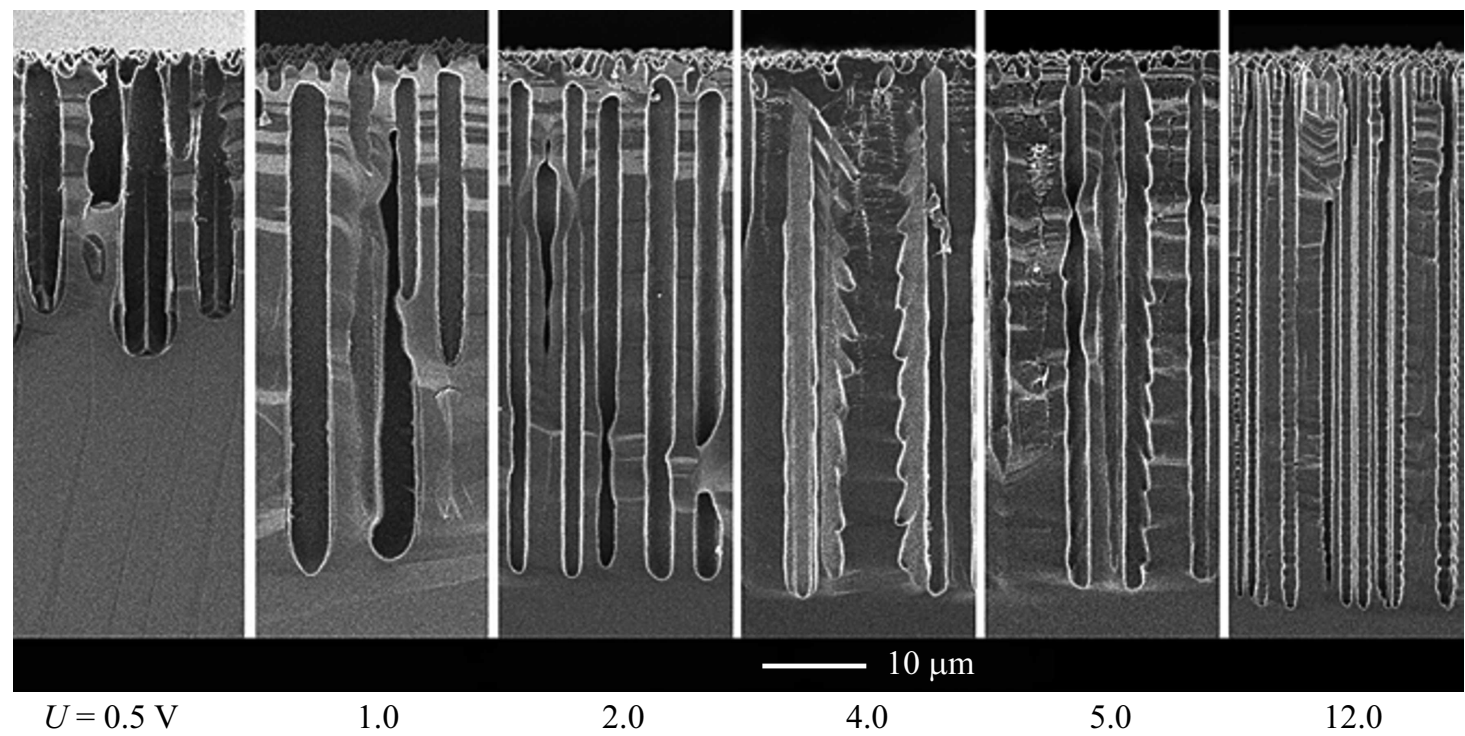

Рис. 2. Зависимость морфологии пор от напряжения при анодировании в водном электролите.

ся довольно много пробойных мезопор, которые в плоскости рисунка ориентированы под углом $45^{\circ}$, т.е. вдоль кристаллографических осей $\langle 100\rangle$. Интересно, что при $U=3$ В источником пробойных мезопор являются не основные каналы, а вертикальные мезопоры. При $U=12$ В их число возрастает и многие из них рождаются на стенках основных каналов. В водном электролите пробойные мезопоры при низком напряжении 2 В не образуются, отсутствуют и боковые ветви (рис. 5,c), а при напряжении 12 В число пробойных мезопор заметно меньше, чем в перекисном электролите (рис. $5, d$ ).

На рис. 6, $a$ и $b$ приведена зависимость среднего диаметра основных каналов $d$ от напряжения $U$. Для водного электролита при повышении напряжения мы видим плавное уменьшение $d$, а для перекисного его резкое падение и последующую стабилизацию на уровне $d \approx 1$ мкм. При близкой поверхностной плотности пор диаметр каналов в перекисном электролите в 1.5-2 раза меньше, чем в водном.

Интересно, что интенсивное ветвление основного канала в обоих электролитах наблюдается только в узком интервале напряжений при $2 \leq U \leq 5 \mathrm{~B}$, когда среднее расстояние между каналами велико. При более высоком напряжении на поверхности зарождается большее число каналов, и их близкое расположение друг к другу подавляет ветвление.

\section{4. Зависимость от напряжения}

Вернемся к данным табл. 1 и 2. На рис. 7, $a$ построена зависимость пористости от напряжения для перекисного 


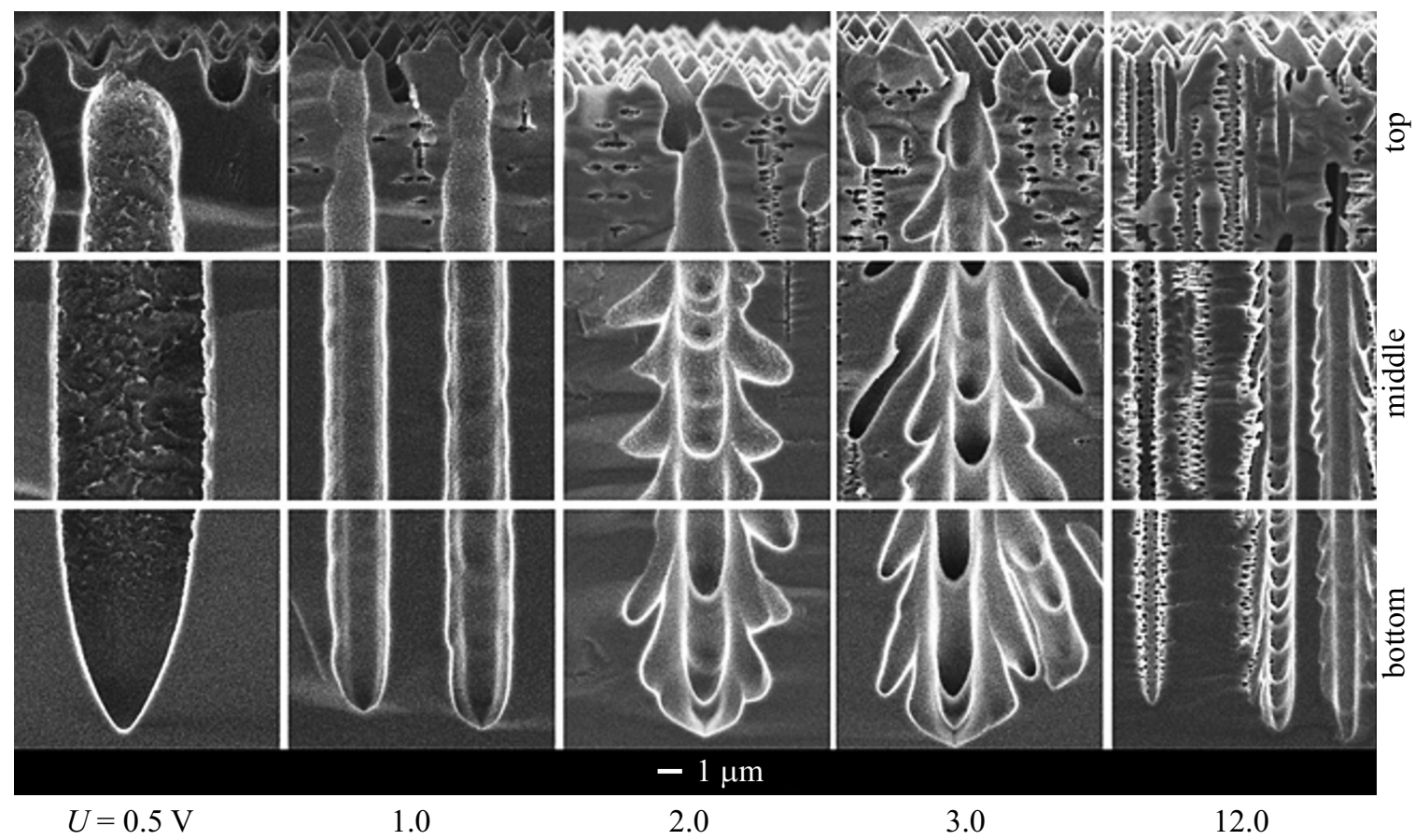

Рис. 3. Поры, образовавшиеся в перекисном электролите при разном напряжении. Увеличенное СЭМ изображение поперечного сечения на разной глубине: в верхней, средней и нижней частях пористого слоя.
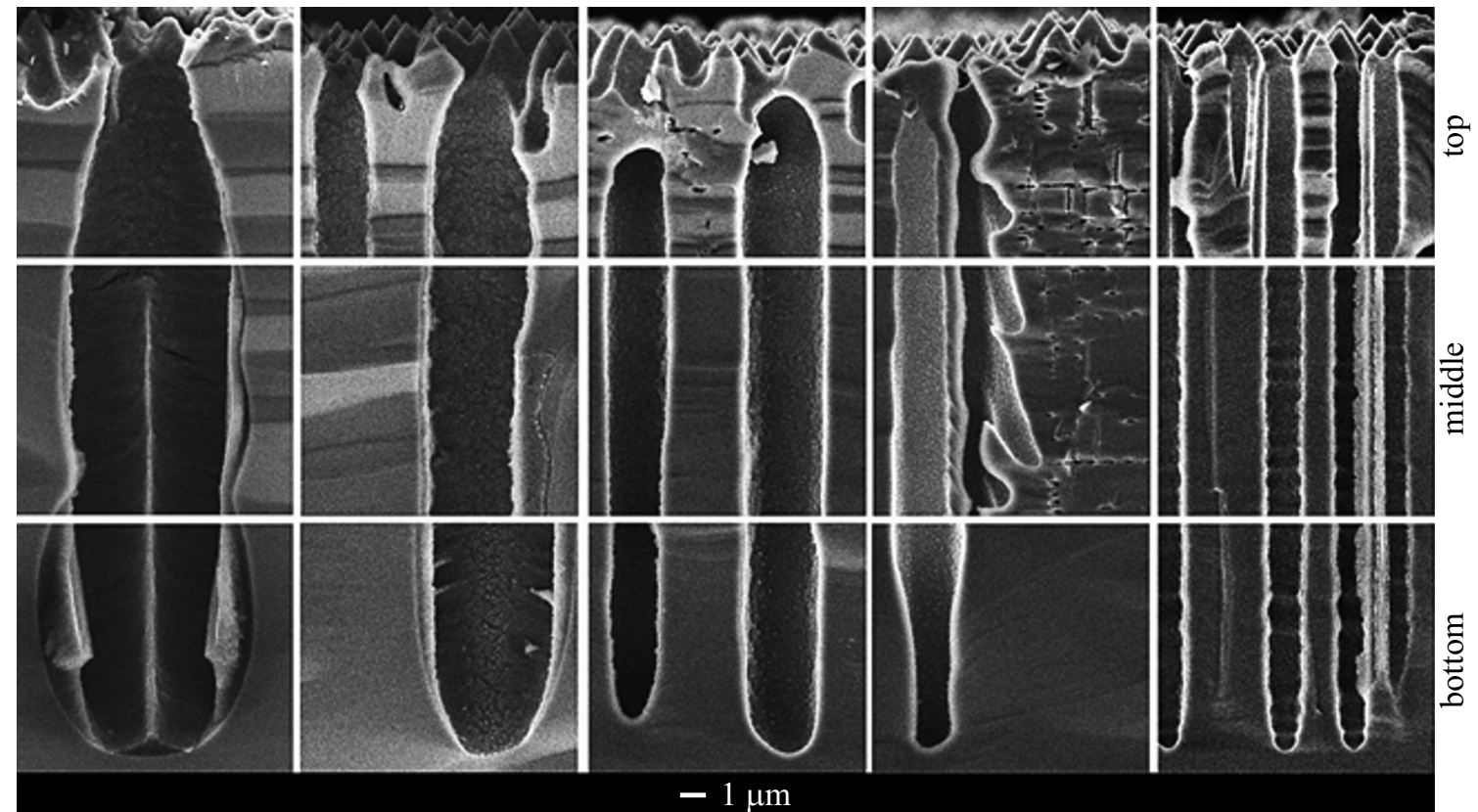

$U=0.5 \mathrm{~V}$

1.0

2.0

3.0

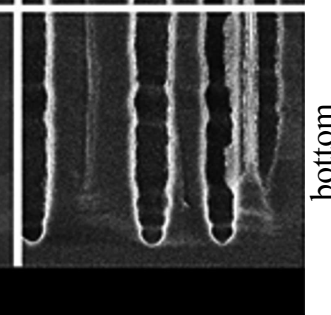

Рис. 4. Поры, образовавшиеся в водном электролите при разном напряжении. Увеличенное СЭМ изображение поперечного сечения на разной глубине: в верхней, средней и нижней частях пористого слоя.

и водного электролитов. Видно, что в обоих случаях пористость не зависит от напряжения, что не удивительно, так как ток поддерживался постоянным. Как известно, для водных электролитов при отсутствии ветвления справедливо соотношение $p=j / j_{p s}$ [8], что следует из того, что травление на дне макропор происходит в режиме электрополировки при локальном токе, равном критическому $j=j_{p s}$. В наших экспериментах, несмотря на то что при некоторых значениях напряжения имеются боковые ветви и пробойные мезопоры, постоянство пористости сохраняется. Абсолютная величина $p$ для перекисного электролита ниже, чем для водного: 

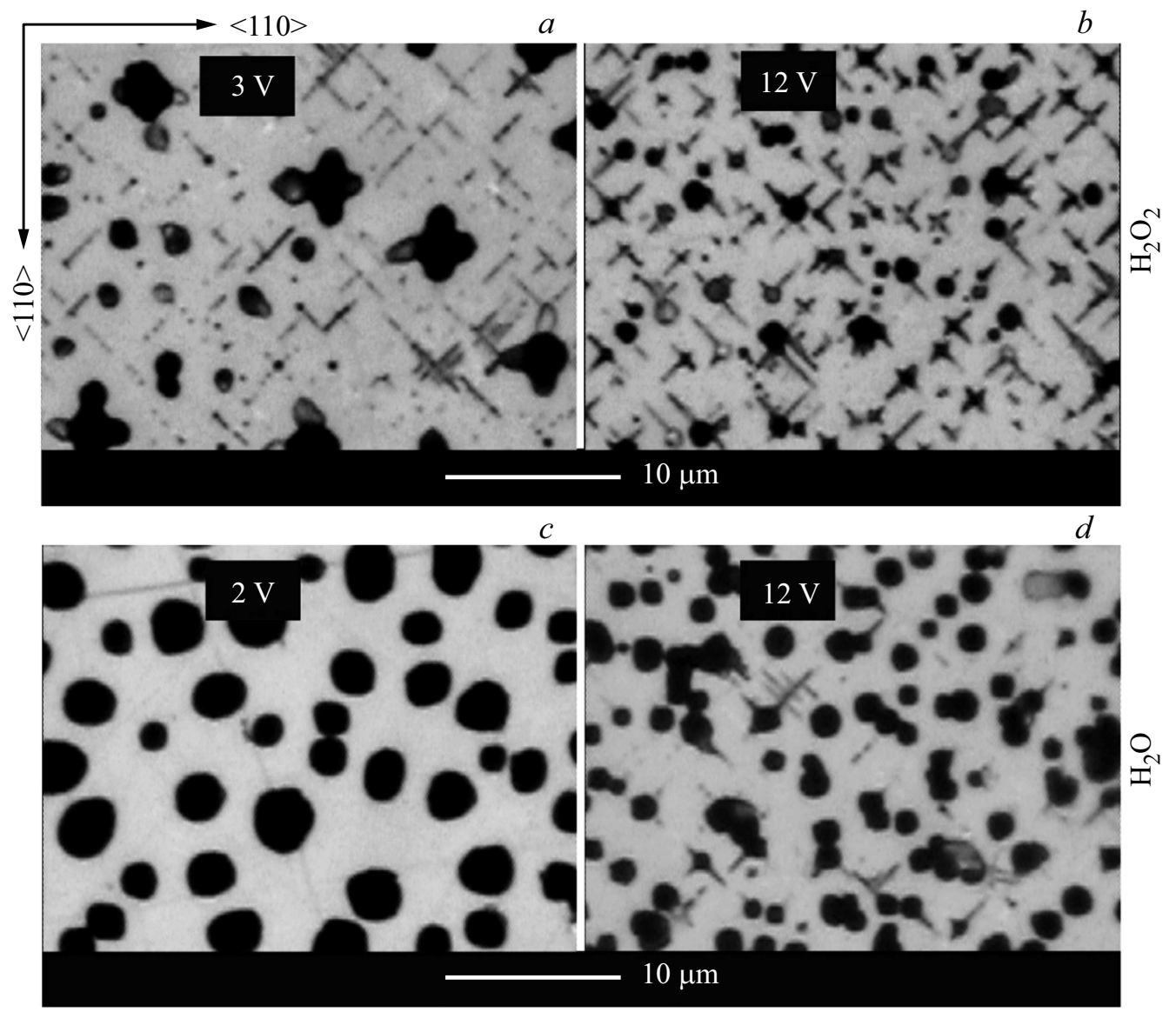

Рис. 5. Вид сверху на образцы, анодировавшиеся в перекисном ( $a$ и $b)$ и в водном $(c$ и $d)$ электролитах при напряжениях, В: $a-3, b, d-12, c-2$. С поверхности удален слой толщиной $\sim 15$ мкм.
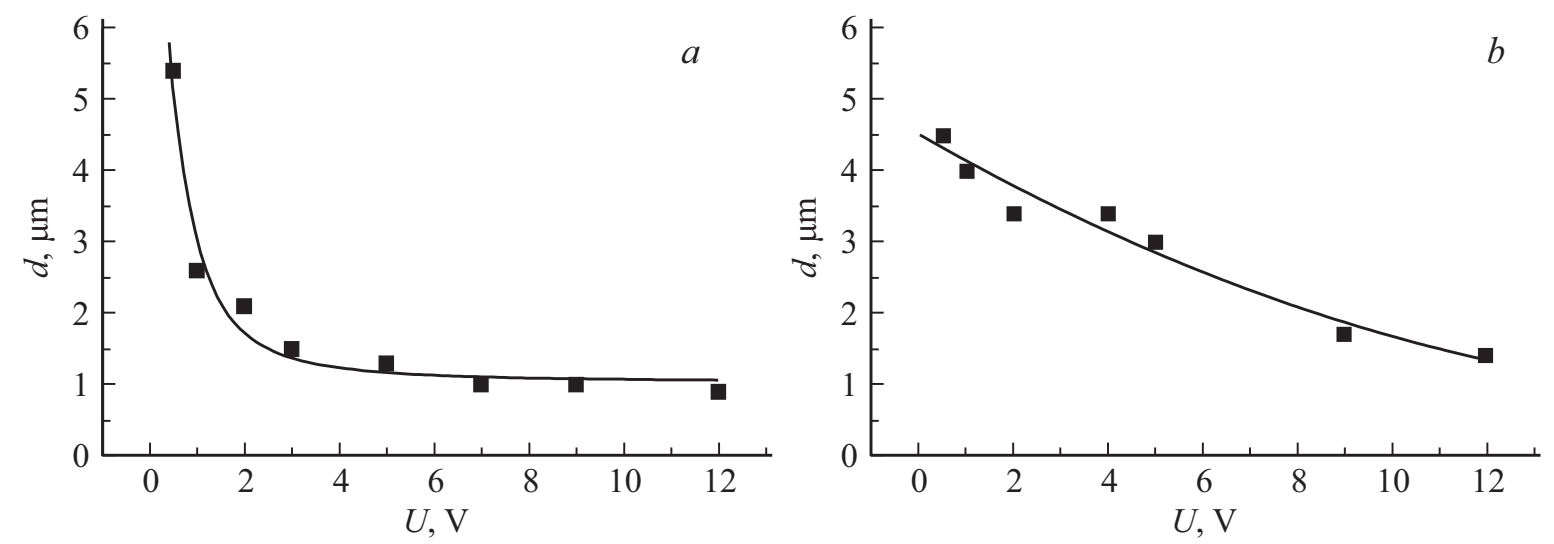

Рис. 6. Зависимость от напряжения среднего значения диаметра каналов: для перекисного $(a)$ и водного $(b)$ электролитов.

$15 \%$ против 23\%, что можно интерпретировать как более высокое $j_{p s}$.

На рис. 7, $c$ приведена зависимость среднего по времени освещения $E_{\mathrm{av}}$ от напряжения. Видно, что для перекисного электролита величина $E_{\mathrm{av}}$ плавно уменьшается с увеличением $U$. Это является следствием того, что более высокое напряжение дает дополнительный вклад в величину тока и для поддержания $j=\mathrm{const}$ требуется меньшая интенсивность подсветки (доля фо- тотока в общем токе снижается). В случае водного электролита для поддержания $j=5.7 \mathrm{MA} / \mathrm{cm}^{2}$ требуется примерно постоянная величина подсветки. С учетом того что анодирование в перекисном и водном электролитах проводилось при разной длительности процесса и изменение $E$ во времени для них носит разный характер, для более корректного сравнения следует использовать интенсивность света в начале процесса анодирования $E_{0}$. На рис. $7, d$ приведена зависимость 

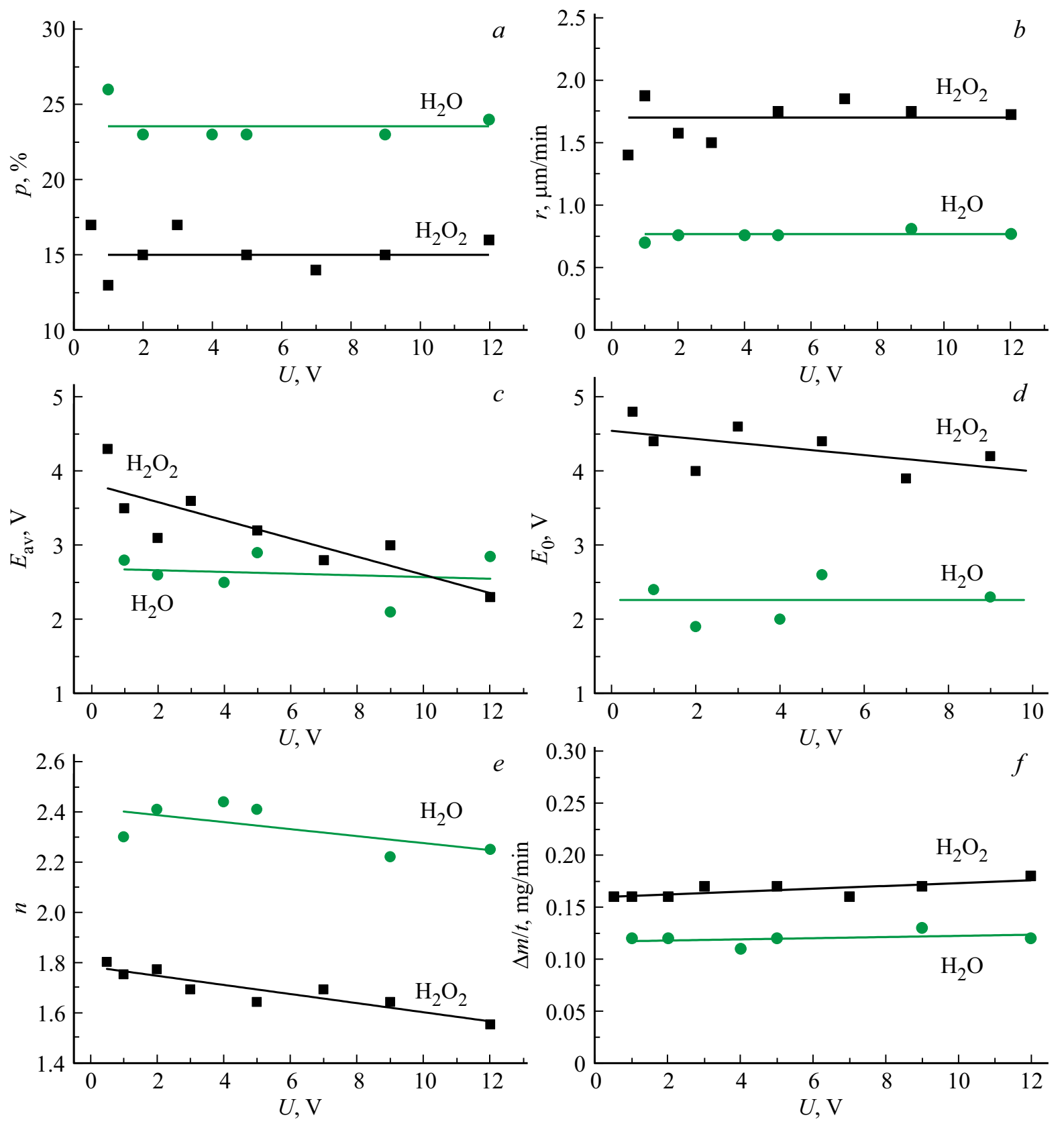

Рис. 7. Сравнение зависимостей от напряжения: пористости $(a)$, скорости травления $(b)$, среднего значения интенсивности света $(c)$, начальной интенсивности света при $t=0(d)$, эффективной валентности $(e)$ и скорости изменения массы $(f)$ для перекисного и водного электролитов. Анодирование в режиме постоянного тока $j=5.7 \mathrm{MA} / \mathrm{cm}^{2}$ в течение $t=40$ и 70 мин соответственно.

$E_{0}$ для двух сравниваемых электролитов, построенная в диапазоне $U=0.5-9 \mathrm{~B}$, из которой хорошо видно, что $E_{0}$ в начале процесса анодирования для перекисного электролита в $\sim 2$ раза превышает $E_{0}$ для водного. Таким образом, очевидно, что для получения одного и того же тока в случае перекисного электролита требуется более высокая интенсивность света или, другими словами, при одинаковой подсветке фототок, протекающий через границу Si-перекисный электролит, меньше, чем через границу Si-водный электролит. На рис. 7, $b$ показана зависимость от напряжения скорости продвижения пор в глубь подложки. Видно, что для обоих электролитов она практически не зависит от напряжения, а ее абсолютное значение для перекисного электролита в $\sim 2$ раза больше, чем для водного. Для перекисного электролита эффективная валентность растворения кремния $n$ (количество электронов, расходуемых на растворение одного атома кремния) (рис. 7,e) всегда меньше двух и монотонно убывает с увеличением $U$ в соответствии с убывающим значением средней интенсивности подсветки $E_{\mathrm{av}}$. На рис. 7, $f$ приведена зависимость от напряжения потери массы образца в единицу времени. Из нее видно, 


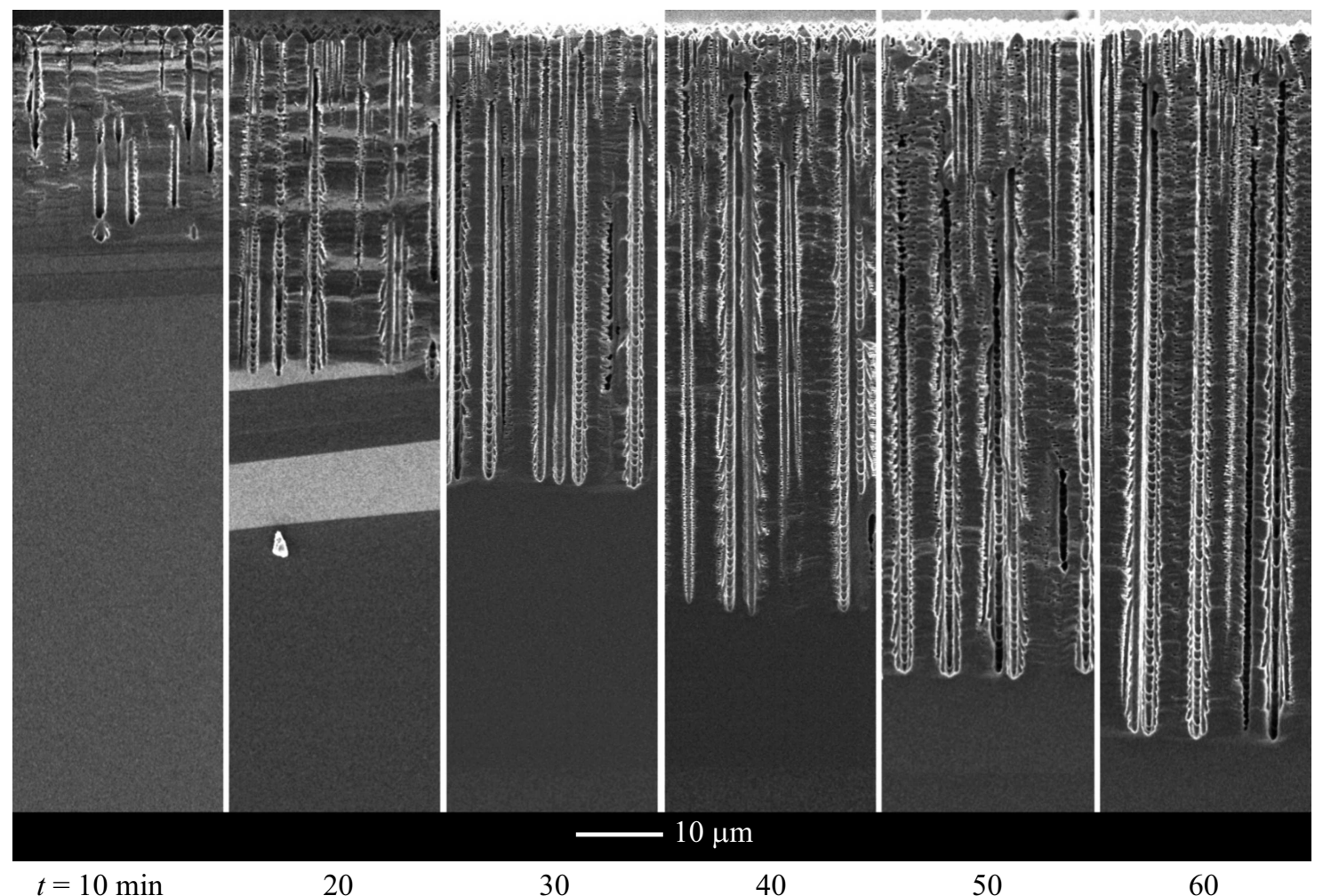

Рис. 8. Зависимость морфологии пор от продолжительности анодирования в перекисном электролите при $U=12 \mathrm{~B}$, $j=5.7 \mathrm{MA} / \mathrm{cm}^{2}$.

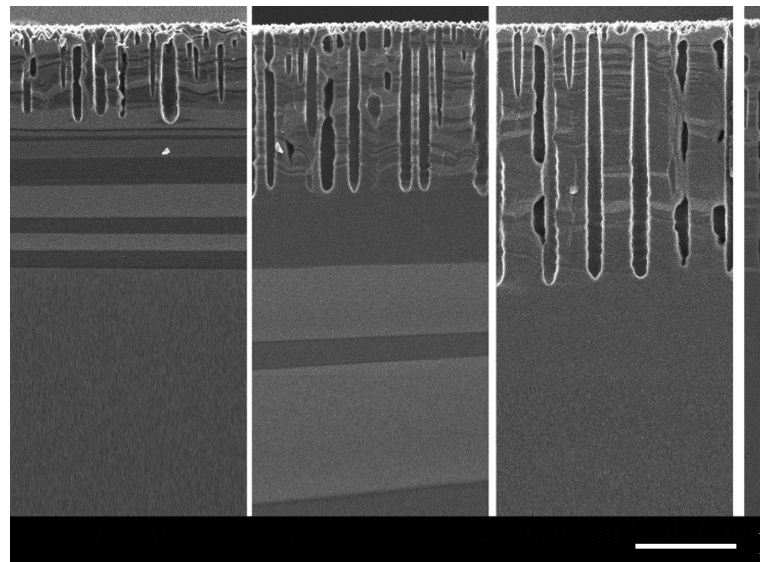

$t=10 \mathrm{~min}$
20
30

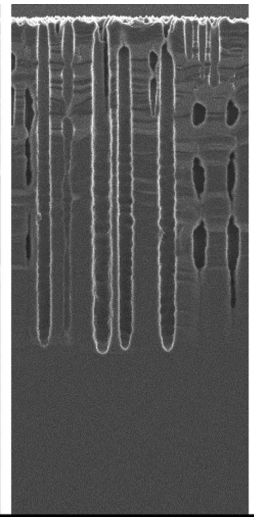

$10 \mu \mathrm{m}$

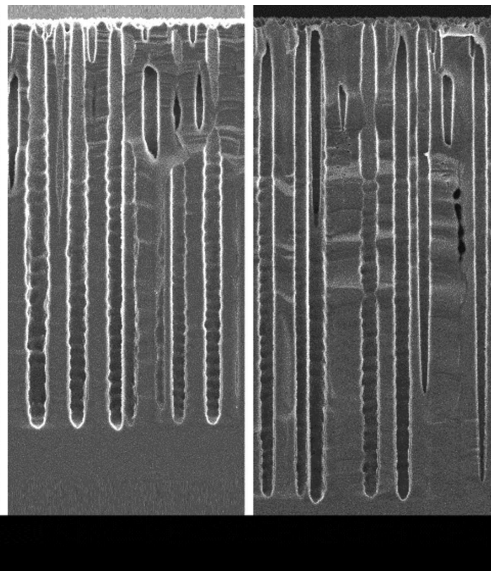

50

60

Рис. 9. Зависимость морфологии пор от продолжительности анодирования в водном электролите при $U=12 \mathrm{~B}, j=5.7$ мА/см²

что при одном и том же токе количество $\mathrm{Si}$, растворенного в перекисном электролите, выше, чем в водном, и в обоих электролитах не зависит от напряжения.

\section{5. Кинетика процесса анодирования}

Для сравнения зависимости результатов анодирования от времени было выбрано два значения напряжения: высокое $U=12$ В и низкое $U=1 \mathrm{~B}$. По-прежнему использовался режим постоянного тока $\mathrm{j}=5.7 \mathrm{MA} / \mathrm{cm}^{2}$.
На рис. 8 и 9 показано, как изменяется морфология пор от длительности травления $t$ в пробойном режиме при $U=12$ В в перекисном и в водном электролитах соответственно. Видно, что в перекисном электролите (рис. 8) со временем появляются новые каналы, зарождающиеся на поверхности, а также увеличивается количество пробойных мезопор. В водном электролите никаких дополнительных пор не обнаруживается (рис. 9). Однако следует отметить выраженную модуляцию диаметра основного канала, которая появляется в нижней части пор при $t \geq 20$ мин. Такое изменение 


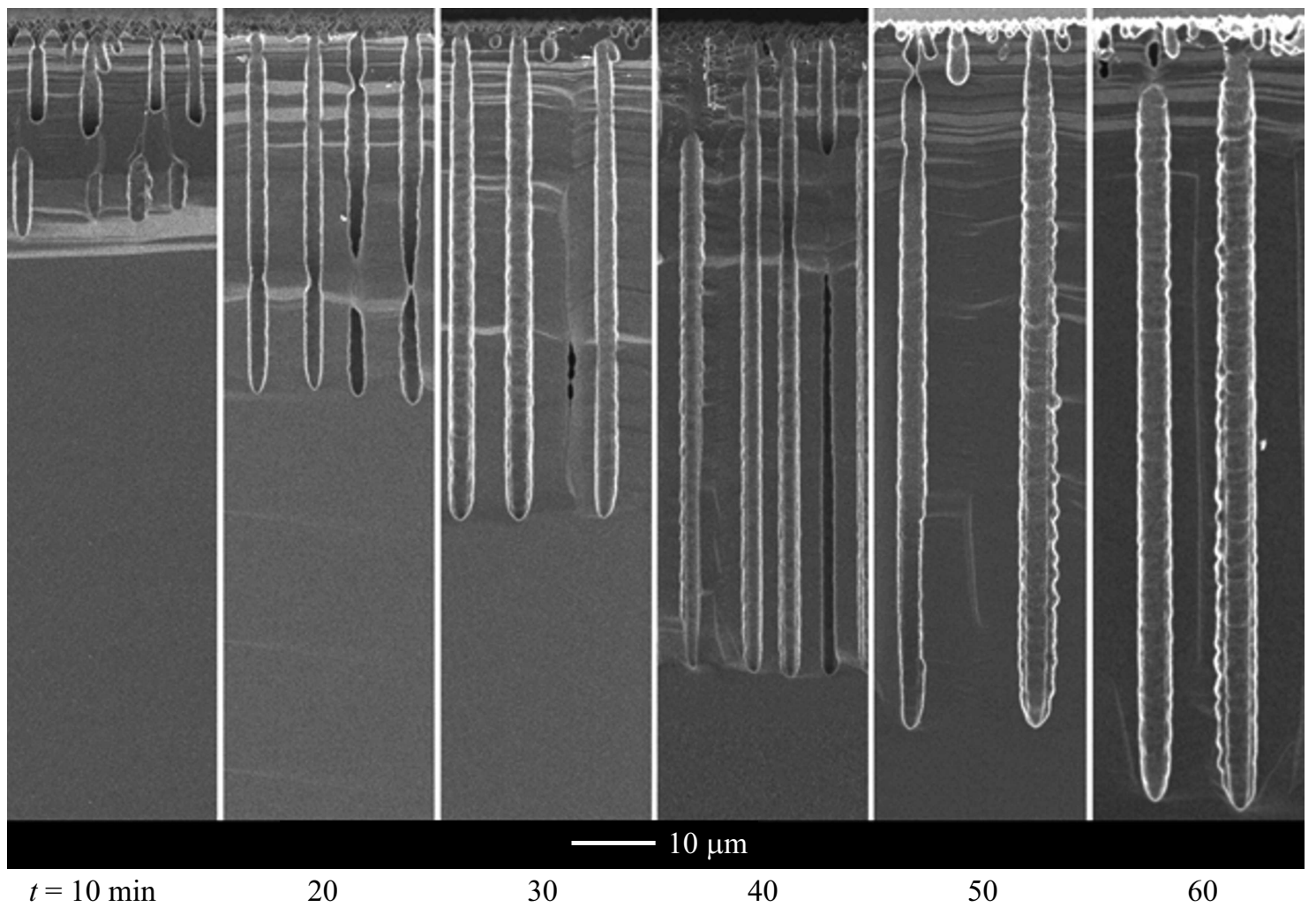

Рис. 10. Зависимость морфологии пор от длительности анодирования в перекисном электролите при $U=1 \mathrm{~B}, j=5.7$ мА/см².

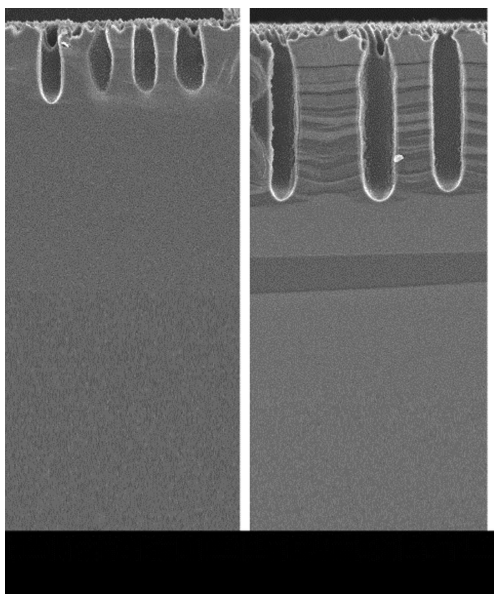

$t=10 \mathrm{~min}$

20

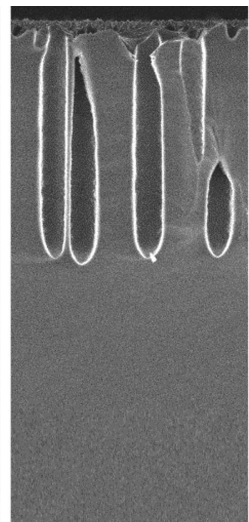

30

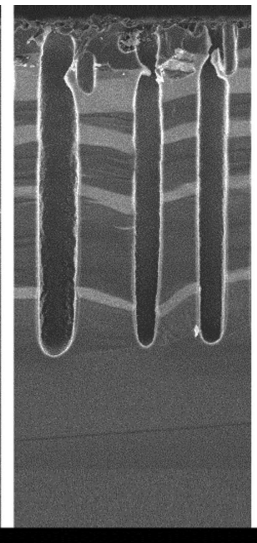

$10 \mu \mathrm{m}$

Рис. 11. Зависимость морфологии пор от длительности анодирования в водном электролите при $U=1 \mathrm{~B}, j=5.7 \mathrm{MA} / \mathrm{cm}^{2}$.

диаметра, по-видимому, связано с колебаниями тока, наблюдающимися при анодировании в водном электролите в режиме пробоя.

На рис. 10 и 11 представлено СЭМ-изображение поперечного сечения пористых структур, полученных при $U=1$ В. Для водного электролита это классические макропоры с гладкими вертикальными стенками (фотопоры), не изменяющие свою форму при увеличении длительности электрохимического травления.

Для перекисного электролита по мере роста $t$ происходит увеличение диаметра каналов и начинают по- являться боковые ветви, что свидетельствует о худшей пассивации стенок в сравнении с водным электролитом. Таким образом, нельзя говорить о полной идентичности морфологии пор, формируемых в водном и перекисном электролитах при низком напряжении.

На рис. 12 представлена зависимость пористости, скорости роста пор, эффективной валентности и массы растворенного кремния от времени анодирования для обоих электролитов. Сравнивается режим травления при низком и высоком напряжении. Из рис. $12, b$ и $d$ видно, что увеличение длительности процесса 

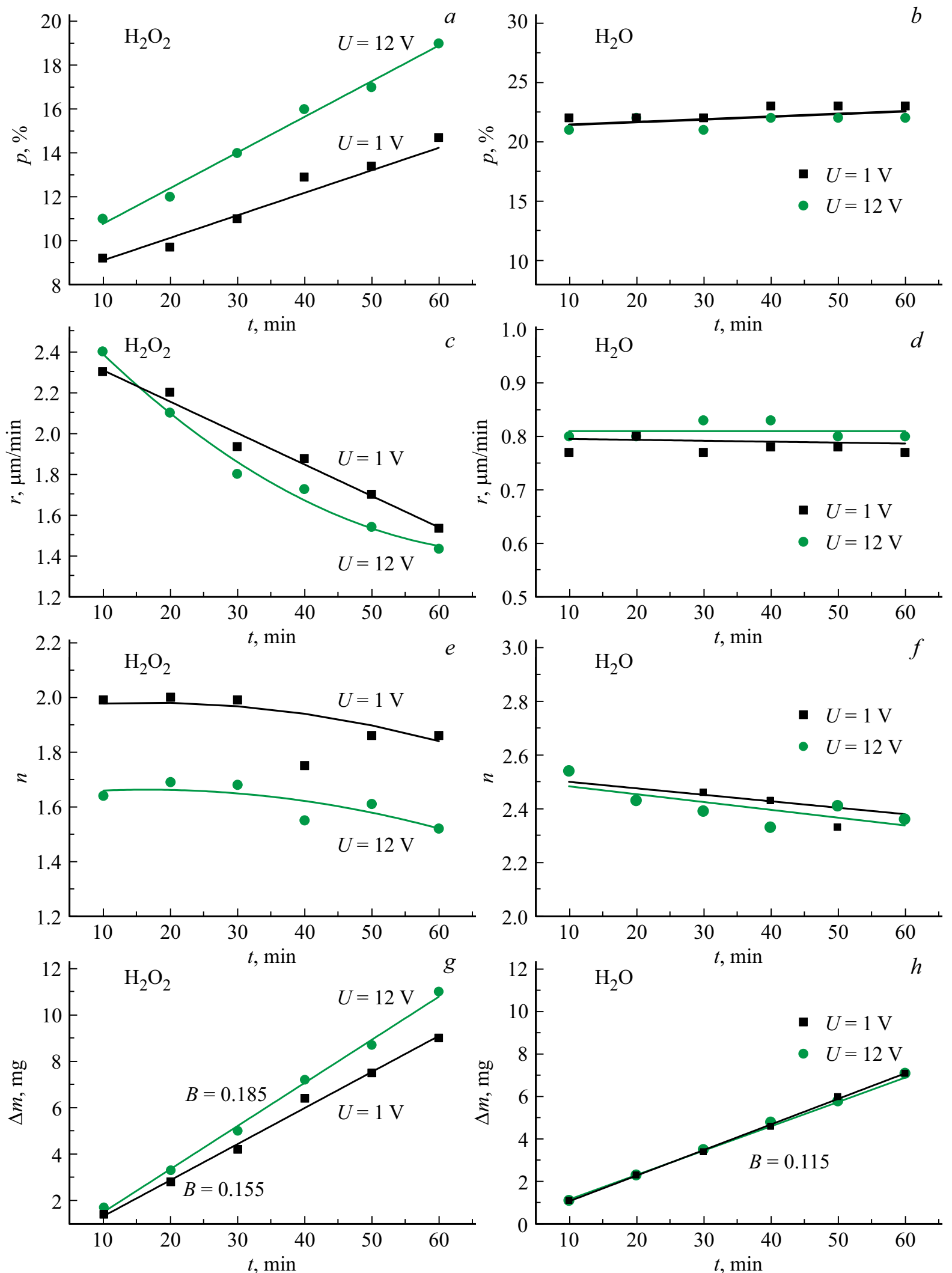

Рис. 12. Зависимость от длительности анодирования в перекисном (левый столбец) и водном (правый столбец) электролитах: пористости $(a, b)$, скорости роста пор $(c, d)$, эффективной валентности $(e, f)$ и потери массы $(g, h)$. Фотоанодирование в режиме постоянного тока $j=5.7 \mathrm{~mA} / \mathrm{cm}^{2}$ при низком $U=1 \mathrm{~B}$ и высоком $U=12$ В напряжениях. 

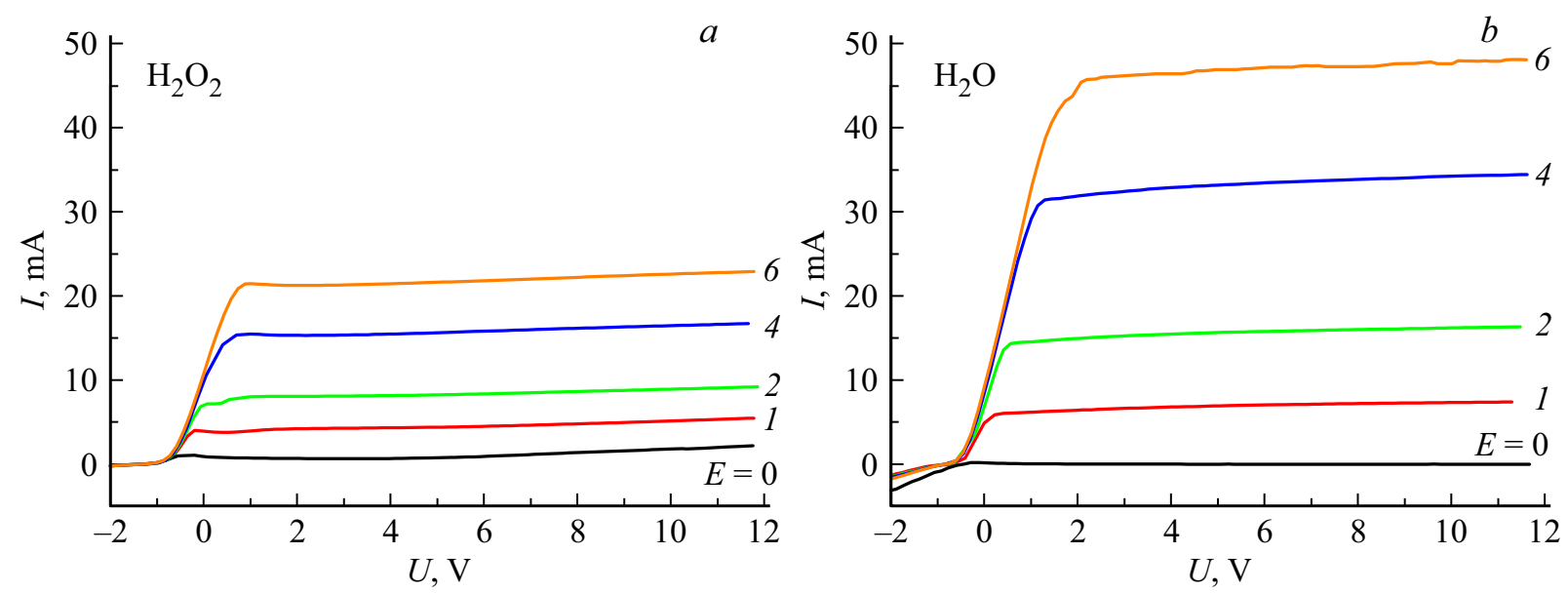

Рис. 13. Вольт-амперные характеристики, записанные при разной интенсивности подсветки $E$ для электролитов на основе $\mathrm{H}_{2} \mathrm{O}_{2}(a)$ и $\mathrm{H}_{2} \mathrm{O}(b)$. Скорость развертки напряжения $1.17 \mathrm{~B} / \mathrm{c}, T=15^{\circ} \mathrm{C}$.
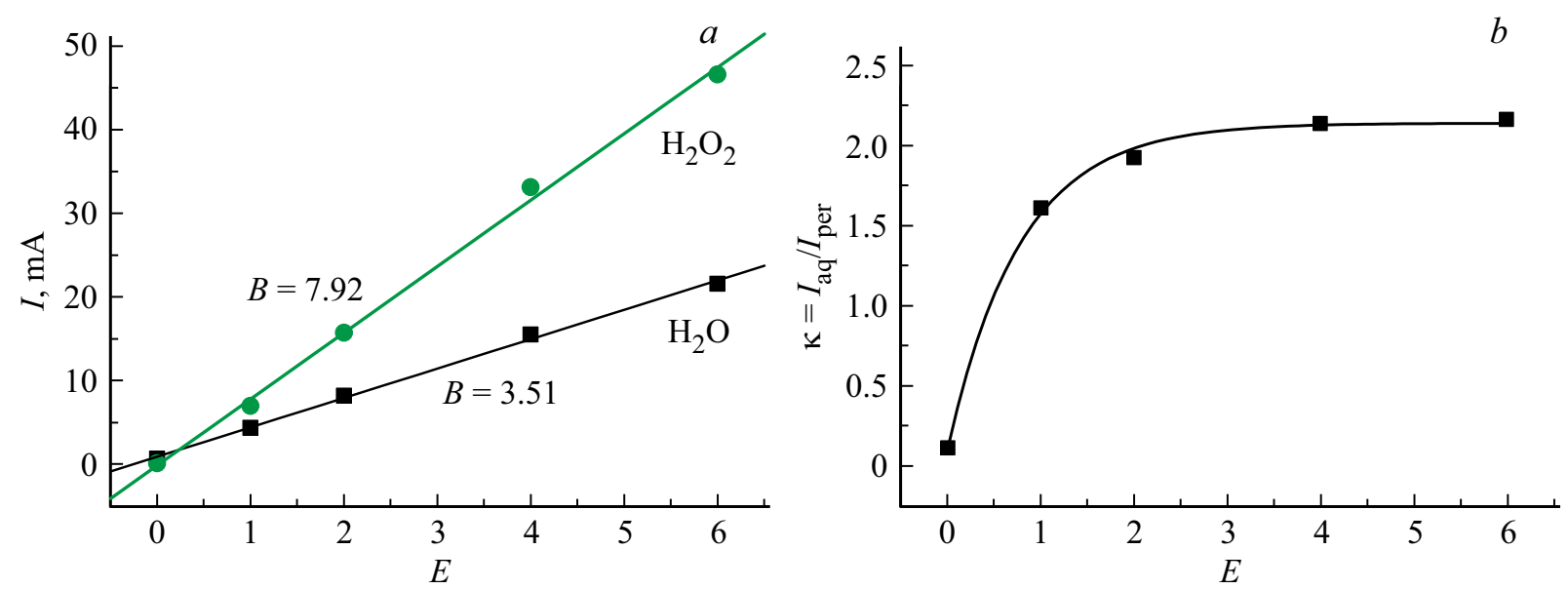

Рис. 14. Зависимость фототока при $U=4$ В от интенсивности света для двух разных электролитов $(a)$ и отношение тока для водного раствора к току для перекисного $(b)$.

для водного электролита практически не приводит к изменению пористости и скорости роста пор ни в режиме фотопор $(U=1 \mathrm{~B})$, ни в пробойном режиме $(U=12 \mathrm{~B})$. Для перекисного электролита пористость увеличивается с ростом $t$ (рис. 12,a), что можно объяснить возрастающим диаметром макропор. В режиме пробоя увеличение пористости происходит быстрее за счет более интенсивного процесса появления новых каналов и вторичных пор. В перекисном электролите скорость роста пор (рис. 12,c), в отличие от водного, уменьшается со временем, что связано с более высоким аспектным отношением, при котором изменение состава электролита в глубине пор играет большую роль $[8,9]$. Эффективная валентность растворения кремния в обоих электролитах немного снижается по мере роста $t$. При этом для водного электролита (рис. 12,f) эффективная валентность $n>2$, и она практически одинакова для низкого и высокого напряжения смещения. В перекисном электролите (рис. 12,e) эффективная валентность в пробойном режиме заметно меньше, чем при $U=1 \mathrm{~B}$. Потеря массы образца от продолжительности анодиро- вания для водного электролита линейно увеличивается с ростом $t$, независимо от $U$ (рис. $12, h$ ). В перекисном электролите изменение массы (рис. $12, g$ ) свидетельствует о более быстром анодном растворении кремния по сравнению с водным электролитом, при этом режиму пробоя, в соответствии с меньшим $n$, присуща более высокая скорость растворения, чем режиму фотопор.

\section{6. Обсуждение результатов}

Проанализируем изменения величины тока при замене водного электролита на перекисный. На рис. 13 приведены вольт-амперные характеристики (BAX), которые записаны для исходных $\mathrm{Si}$ образцов. Из них хорошо видно, что при одной и той же интенсивности света ток в случае перекисного электролита значительно меньше, чем в случае водного. Заметим, что снижение фототока для перекисного электролита наблюдали и авторы работы [3]. 

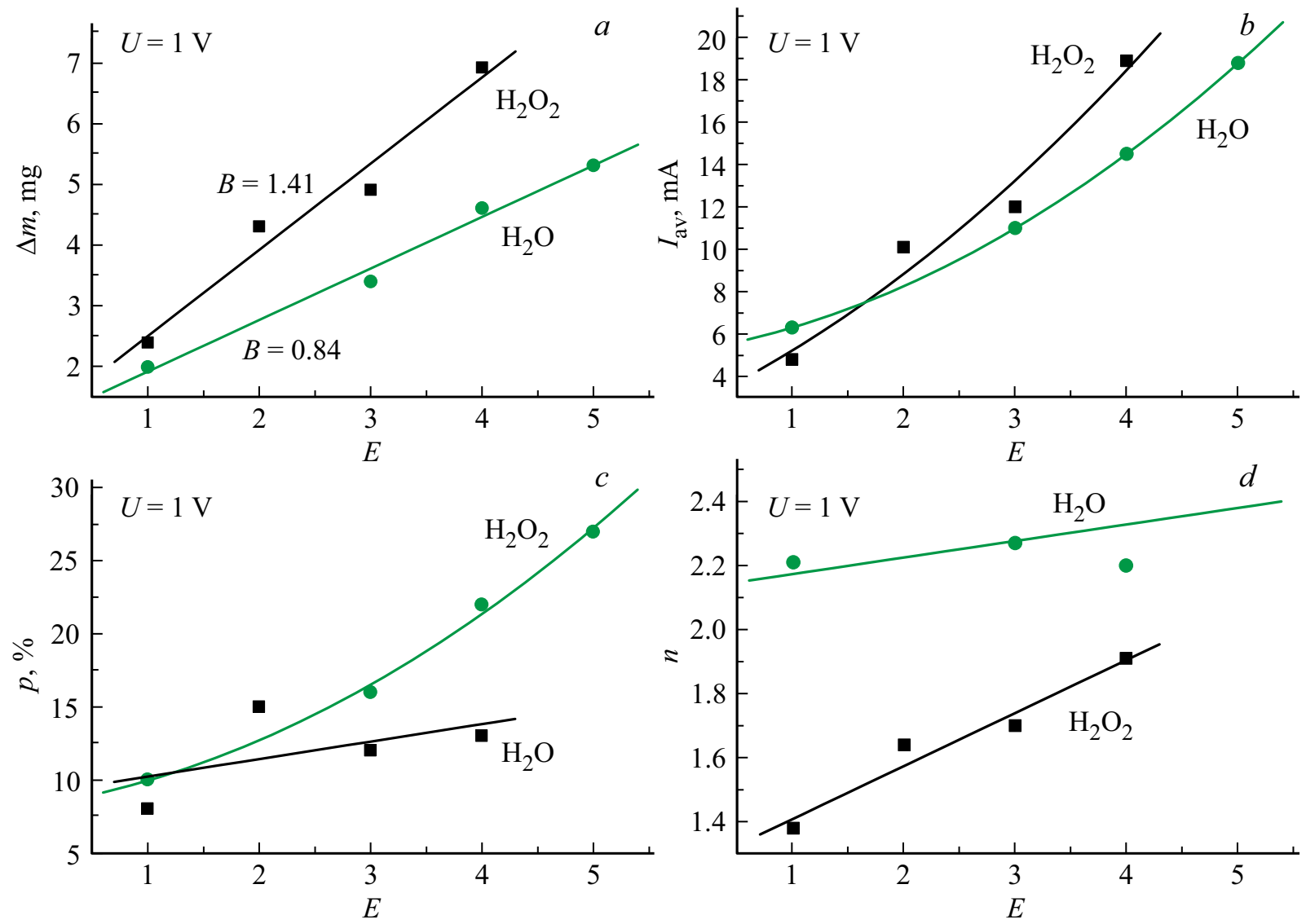

Рис. 15. Сравнение зависимостей: $a-$ количества растворенного кремния, $b-$ среднего тока, $c-$ пористости и $d-$ эффективной валентности от интенсивности света $E$ для двух электролитов. Анодирование в режиме $E=$ const при смещении $U=1 \mathrm{~B}$ в течение $t=40$ мин.

На рис. 14, $a$ построена зависимость тока в области насыщения (при $U=4 \mathrm{~B}$ ) от интенсивности света $E$, а на рис. $14, b$ отношение этих токов в зависимости от $E$.

Наклон прямой $B$, аппроксимирующей зависимость $I(E)$ для тока в водном растворе $I_{\text {aq }}$, более чем в 2 раза превышает таковой для перекисного $I_{\text {per }}$ (рис. $14, a$ ), а отношение токов $\kappa=I_{\mathrm{aq}} / I_{\mathrm{per}}$ по мере увеличения интенсивности света стремится к постоянному значению $\kappa=2.14$. Отсюда следует, что квантовая эффективность $\eta$, т.е. число носителей заряда, рожденных при поглощении одного фотона, дошедших до границы Siэлектролит и формирующих фототок во внешней цепи, в случае перекисного электролита в $\sim 2$ раза ниже, чем в случае водного. Заметим, что для темнового тока картина другая: в перекисном растворе темновой ток в 9 раз больше, чем в водном. Для анодного растворения кремния в водных растворах плавиковой кислоты при токах, соответствующих режиму порообразования, хорошо известен эффект умножения тока $[8,10-12]$, при котором число носителей заряда в 2 раза превышает число поглощенных квантов света [13]:

$$
\mathrm{Si}+6 \mathrm{HF}+2 \mathrm{~h}^{+} \rightarrow \mathrm{H}_{2} \mathrm{SiF}_{6}+4 \mathrm{H}^{+}+2 \mathrm{e}^{-} .
$$

В режиме порообразования водному электролиту присуще $\eta=2$, откуда из сравнения данных, представлен- ных на рис. 13 и 14, можно заключить, что для перекисного электролита квантовая эффективность $\eta=1$.

Согласно модели Геришера [11], при анодном растворении одного атома кремния в водном растворе $\mathrm{HF}$ помимо инжекции дырки в валентную зону в процессе участвует дублирующий электрон, который инжектируется в зону проводимости. Суммарный эффект состоит в удвоении числа электронов, формирующих ток, а эффективная валентность растворения $n=2$. Таким образом, двухвалентное анодное растворение кремния тесно связано с вышеупомянутым умножением тока. Изменение стехиометрии растворения $\mathrm{Si}$ в присутствии $\mathrm{H}_{2} \mathrm{O}_{2}$, согласно модели Коласинского [3], объясняется тем, что дублирующий электрон захватывается молекулой $\mathrm{H}_{2} \mathrm{O}_{2}$ и не участвует в протекающем токе, а образующаяся на поверхности кремния группа $\mathrm{OH}^{-}$ служит катализатором растворения кремния в воде. Таким образом, нет удвоения тока $(\eta=1)$, и эффективная валентность растворения $n=1$. Для водного раствора HF результирующий эффект состоит в том, что при поглощении одного фотона в цепи появляется 2 электрона, и они оба расходуются на растворение одного атома кремния:

$$
1 h v \underset{\eta=2}{\longrightarrow} 2 e \underset{n=2}{\longrightarrow} 1 \mathrm{Si}
$$



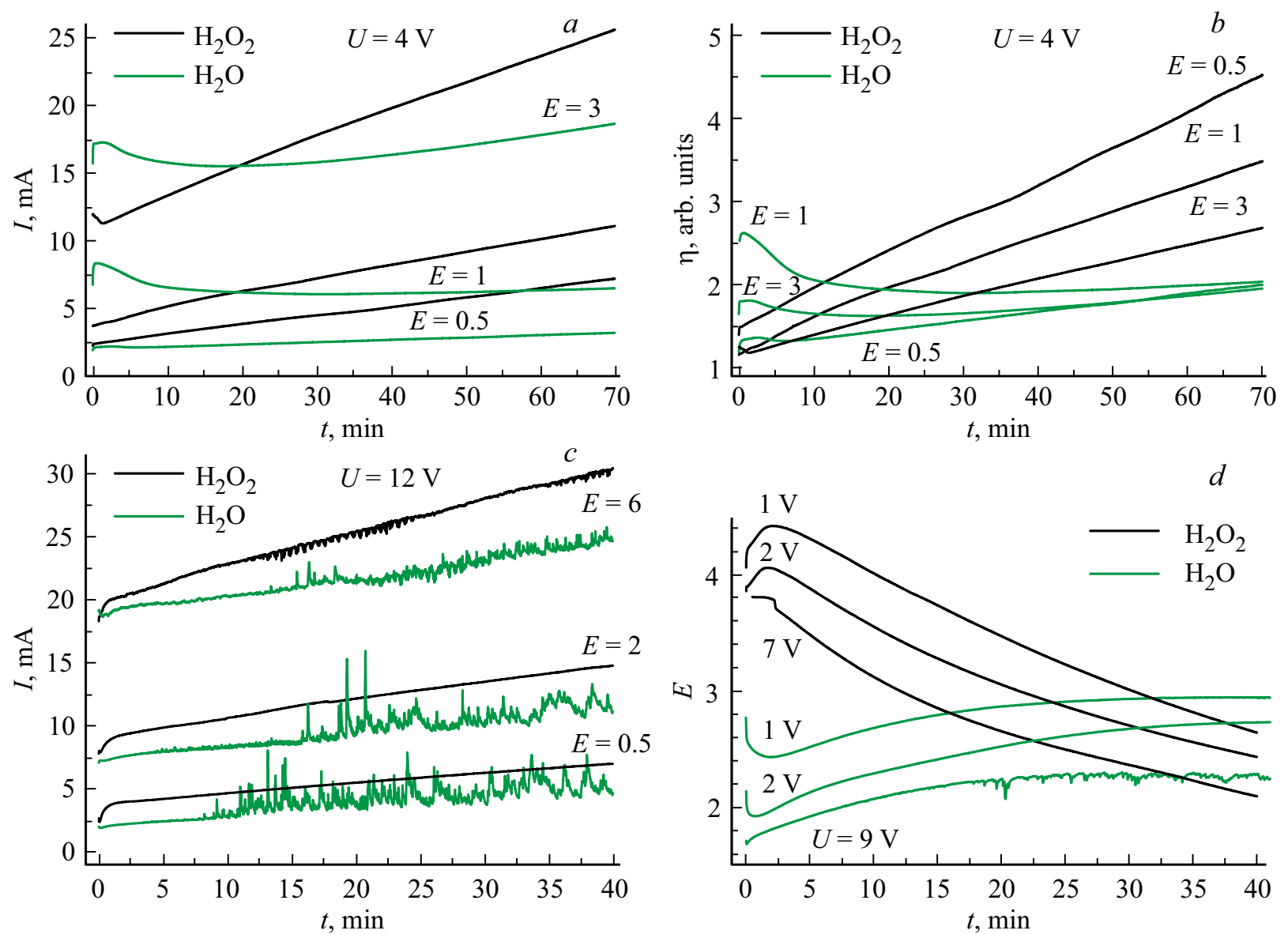

Рис. 16. Сравнение зависимостей: тока от времени в режиме анодирования при постоянной интенсивности света $E$ при $U=4 \mathrm{~B}(a)$ и при $U=12 \mathrm{~B}(c)$, кажущейся квантовой эффективности при $U=4 \mathrm{~B}(b)$, интенсивности света при анодировании в режиме постоянного тока $(I=16$ мА $)$ при разных напряжениях смещения $U$, указанных возле кривых $(d)$.

Для перекисного раствора НF на один фотон приходится один электрон и один растворенный атом кремния:

$$
1 h v \underset{\eta=1}{\longrightarrow} 1 e \underset{n=1}{\longrightarrow} 1 \mathrm{Si} \text {. }
$$

В перекисном электролите параллельно протекают оба процесса: (2) и (3) с разным вкладом, зависящим от уровня освещенности или приложенного напряжения, что проявляется в том, что эффективная валентность находится в диапазоне $1<n<2$. Однако независимо от относительной роли каждого из этих процессов и соответственно протекающего тока для растворения одного атома кремния требуется один фотон, т. е. потеря массы образца должна определяться только интенсивностью света и для обоих электролитов быть одинаковой. Однако, как следует из проведенных экспериментов, это не так. На рис. 15 приведены результаты, полученные при анодировании в режиме постоянной подсветки.

Из рис. 15, a видно, что масса кремния, растворенного при анодировании в перекисном электролите, больше и при увеличении интенсивности света возрастает быстрее, чем в водном. Это является следствием того, что средний ток за время процесса анодирования больше для перекисного электролита, чем для водного (рис. $15, b)$. Обратное соотношение наблюдается только при малой подсветке при $E<1.7$. Из рис. $15, c$ и $d$ видно, что пористость и эффективная валентность для водного электролита больше, чем для перекисного. Оба параметра увеличиваются с ростом $E$ : пористость быстрее для водного электролита, валентность для перекисного.

Проанализируем зависимость тока анодирования от времени. Из рис. 16, a видно, что в начальной фазе электрохимического травления $I_{\mathrm{aq}} \geq I_{\mathrm{per}}$, что согласуется с данными ВАХ на рис. 13. Так как ток в случае перекисного электролита быстро увеличивается, то уже через 20 мин он становится больше, чем для водного. Формальный расчет квантовой эффективности, как отношения $I / E$, представлен на рис. $16, b$ в относительных единицах. Из него следует, что кажущаяся эффективность $\eta$ для водного раствора $\mathrm{HF}$ стремится со временем к постоянному значению, не зависящему от $E$, а для перекисного линейно возрастает. В последнем случае большей интенсивности света соответствует более низкое $\eta$. Следует обратить внимание на то, что при высоком напряжении, соответствующем пробою, начальный ток резко увеличивается и уже с 
первых минут травления $I_{\text {per }}>I_{\text {aq }}$ (рис. 16,c). При анодировании в режиме постоянного тока изменение освещенности $E$ происходит в полном соответствии с вышеприведенными данными для $I$, а именно, если в режиме $E=$ const ток $I$ со временем возрастает, то в режиме $I=$ const интенсивность света $E$ со временем уменьшается, и наоборот (рис. 16, $d$ ). При увеличении напряжения кривые $E(t)$ для обоих электролитов сдвигаются вниз, что связано со снижением доли фототока в общем токе. Таким образом, в выражении (3) выполняется только правая часть, определяющая эффективную валентность. Перекись водорода является сильным окислителем. Реакция растворения кремния во фторидном растворе в присутствии $\mathrm{H}_{2} \mathrm{O}_{2}$ запускается под воздействием света и напряжения. Увеличение тока со временем свидетельствует о самоускоряющемся каталитическом процессе, который может быть связан с появлением радикалов, обусловленных разложением перекиси водорода.

\section{7. Заключение}

Присутствие в растворе НF окислителя в виде перекиси водорода оказывает значительное влияние на процесс порообразования в $n$-Si в условиях освещения обратной стороны образца собственным светом. Прежде всего происходит изменение стехиометрии реакции анодного растворения кремния, которое приводит к снижению эффективной валентности до $n=1$. Изменение фототока носит более сложный характер, что, повидимому, определяется реакциями, протекающими в электролите и на поверхности $\mathrm{Si}$. Введение в электролит перекиси водорода приводит к усилению анизотропии, которое выражается в уменьшении диаметра макропор и увеличении их глубины. Возрастает средняя скорость роста пор, которая при фотоанодировании в режиме $j=5.7 \mathrm{MA} / \mathrm{cm}^{2}$ составляет $1.7 \mathrm{M \kappa м} / \mathrm{Mин,} \mathrm{что} \mathrm{в} 2.2$ раза выше, чем в электролите с той же концентрацией $\mathrm{HF}$, но на основе воды. При этом пористость оказывается в 1.53 раза меньше. Действие окислителя $\mathrm{H}_{2} \mathrm{O}_{2}$ приводит к ухудшению пассивации вертикальных стенок макропор и появлению вторичных пор. Число пробойных мезопор растет по мере увеличения напряжения смещения и по мере увеличения длительности анодирования. Выраженное ветвление наблюдается только в узком диапазоне напряжения и интенсивности света. Напряжение смещения оказывает более сильное влияние на анодирование в перекисном электролите. В отличие от водного электролита изменение со временем пористости, скорости роста пор, эффективной валентности и количества растворенного кремния происходит быстрее при высоком напряжении, чем при низком.

Авторы выражают благодарность Д.Н. Горячеву и В.П. Улину за ознакомление с рукописью и полезные замечания.

\section{Список литературы}

[1] X.Q. Bao, J.W. Jiao, J. Zhou, Y.L. Wang. Electrochimica Acta, 52, 6728 (2007).

[2] D.H. Ge, J.W. Jiao, S. Zhang, Y.L. Wang. Electrochem. Commun., 12, 603 (2010)

[3] C. Cozzi, G. Polito, K.W. Kolasinski, G. Barillaro. Adv. Funct. Mater., 27, 1604310 (2017).

[4] C. Cozzi, G. Polito, K.W. Kolasinski, G. Barillaro. ECS Transactions, 77 (5), 199 (2017).

[5] C. Cozzi, G. Polito, L.M. Strambini, G. Barillaro. Electrochimica Acta, 187, 552 (2016).

[6] Г.В. Ли, Е.В. Астрова, А.И. Лихачев. ФТП, 53 (13), 1614 (2018).

[7] Е.В. Астрова, Н.Е. Преображенский, Г.В. Ли, С.И. Павлов. ФТП, 52 (3), 414 (2018).

[8] V. Lehmann. Electrochemistry of Silicon (Weinheim, Wiley-VCH, 2002).

[9] G. Barillaro, F. Pieri. J. Appl. Phys., 97, 116105 (2005).

[10] H. Gerischer, M. Lubke. Ber. Bunsenges. Phys. Chem., 91, 394 (1987).

[11] H. Gerischer, P. Allongue, V.C. Kieling. Ber. Bunsenges. Phys. Chem., 97, 753 (1993).

[12] K.W. Kolasinski. Surf. Sci., 603, 1904 (2009).

[13] M. Matsumura, S.R. Morrison. J. Electroanal. Chem., 147, 157 (1983).

Редактор А.Н. Смирнов

\section{Photoanodization of $n$-Si in the presence of hydrogen peroxide: voltage dependence}

\author{
G.V. Li, E.V. Astrova, A.I. Lihachev
}

loffe Institute, 194021 St. Petersburg, Russia

Abstract The laws of electrochemical etching of slightly doped $n$-Si under the backside illumination were investigated using a solution with a low concentration of HF and a high concentration of hydrogen peroxide. The obtained data are compared with those for a control electrolyte based on water. The dependence of morphology for the self-organized macropores, their growth rate, porosity, effective valence and the amount of dissolved silicon on the voltage is investigated. Studies of the anodization kinetics at low and high bias voltages were carried out. It was found that with the same illumination, the initial photocurrent in the peroxide electrolyte is approximately 2 times less than in the aqueous, which allows us to speak about a lower quantum efficiency. However, with the etching time, the current in the peroxide electrolyte increases strongly and becomes larger than in the control one based on $\mathrm{H}_{2} \mathrm{O}$. It has been shown that in a solution of HF based on $\mathrm{H}_{2} \mathrm{O}_{2}$, the growth rate of in depth is more than 2 times higher as compared with a solution of $\mathrm{HF}$ based on $\mathrm{H}_{2} \mathrm{O}$, and the porosity is lower. Vertical channels of macropores have a diameter smaller than in the case of macropores formed in the aqueous electrolyte, and their walls are poorly passivated, which causes branching and formation of secondary mesopores, the number of which increases with voltage. The effective valence of silicon dissolution in the presence of $\mathrm{H}_{2} \mathrm{O}_{2}$ decreases to values less than 2. The obtained results are interpreted within the framework of Gerischer and Kolasinski models. 